\title{
Function Assessment for Rheumatoid Thumb Deformity
}

\author{
Ryo Oda*, Daigo Taniguchi, Hiroyoshi Fujiwara, Shogo Toyama, Daisaku Tokunaga, \\ Toshikazu Kubo \\ Department of Orthopaedics, Graduate School of Medical Science, Kyoto Prefectural University of Medicine, \\ Kyoto, Japan \\ Email: ${ }^{*}$ roda@koto.kpu-m.ac.jp
}

Received 22 July 2015; accepted 25 August 2015; published 28 August 2015

Copyright (C) 2015 by authors and Scientific Research Publishing Inc.

This work is licensed under the Creative Commons Attribution International License (CC BY). http://creativecommons.org/licenses/by/4.0/

(c) (i) Open Access

\section{Abstract}

Objective: Nalebuff's type I deformity of the rheumatoid thumb, which is the most common thumb deformity with rheumatoid arthritis, can be classified into three stages according to the range of motion of the thumb. However, a functional assessment for each stage has never been undertaken. Methods: The ranges of motion of the thumb metacarpophalangeal and interphalangeal joints were evaluated to determine Nalebuff's clinical stage, and both the Modified Kapandji Index (MKI) and the simple test for evaluating hand function (STEF) were used to evaluate hand function in 32 rheumatoid arthritis patients with type I deformity. We assessed hand function in each stage, and examined the relationship between the three clinical stages and dysfunction of the hand. Results: The scores for both MKI and STEF were significantly reduced in parallel with advancing stage of thumb deformity. Conclusion: Nalebuff's staging system is also useful for reflecting the level of thumb function.

\section{Keywords}

Rheumatoid Arthritis, Thumb Deformity, Function Assessment

\section{Introduction}

Approximately $60 \%$ to $80 \%$ of the patients with rheumatoid arthritis (RA) complain of functional disability due to deformities of their fingers [1]. The thumb is the most important digit of the hand, and deformity of the thumb is one of the most frequent conditions affecting patients with RA [2]. Rheumatoid Thumb Deformities affect $40 \%$ $50 \%$ of functional exacerbation in upper extremities [3]. Therefore, preserving and recovering thumb functions are very important in the practice of RA.

\footnotetext{
${ }^{*}$ Corresponding author.
}

How to cite this paper: Oda, R., Taniguchi, D., Fujiwara, H., Toyama, S., Tokunaga, D. and Kubo, T. (2015) Function Assessment for Rheumatoid Thumb Deformity. Open Journal of Rheumatology and Autoimmune Diseases, 5, 92-96. 
Three types of rheumatoid thumb deformities were proposed by Nalebuff in 1968, and they were widely considered as a standard classification of the rheumatoid thumb [2] [4]. In Nalebuff's classification, type I deformity of the rheumatoid thumb was called common rheumatoid thumb deformity, also known as $\mathrm{Z}$ deformity or boutonniere deformity of the thumb. It had been reported that $50 \%-74 \%$ of the finger deformities were type I deformity of the thumb [5] [6]. It can be classified into early, moderate and advanced stages, depending on whether the deformity was passively correctable [4] [5] In its early stage, both interphalangeal (IP) and metacarpophalangeal (MP) joints were passively correctable. In the moderate stage, the MP joint was fixed, but the IP joint was correctable; and in the advanced stage, both joints were fixed. The three clinical stages, which were based on the pathophysiology of the type I deformity, were widely used to give their usefulness for guiding selection of the most appropriate surgical treatment. However, a functional assessment for each stage had never been done. A functional assessment was very important to determine the appropriate treatment approach, including conservative treatment. In this study, we assessed hand function in each stage, and examined the relationship between the three clinical stages and dysfunction of the hand.

\section{Patients and Methods}

RA patients with type I deformity were included in the study, and the data were collected. Eligible patients fulfilled the American Rheumatism Association 1987 criteria for RA [7]. Patients who had severe digital finger deformity (for example, more than $20^{\circ}$ ulnar deviation, uncorrectable swan neck deformity or uncorrectable boutonniere deformity) were excluded. Patients with severe RA disease activity were also excluded to permit exact assessment of thumb function. The ranges of motion of the thumb MP and IP joints of patients included in the study were measured, and patients were classified into three disease stages (early, moderate and advanced) for type I deformity of the rheumatoid thumb.

Hand function was evaluated with the Modified Kapandji Index (MKI) [8] [9] and the simple test for evaluating hand function (STEF) [10] [11]. The MKI score is obtained by summing the scores of three tests, but in this study to assess thumb function, only opposition of the thumb was performed, and scored from 0 (impossible to do) to 10 (completely accomplished). The test consists of touching the four long fingers with the tip of the thumb; the score is 1 when the lateral side of the middle phalanx of the index finger is reached and 10 when it reaches the distal volar crease of the hand.

STEF was designed to evaluate the speed of manipulating objects using one upper limb, and it is widely used to assess hand function in Japan. Patients must grasp or pinch the objects and carry them to a designated area 10 times; the time to complete the work is recorded. There are 10 objects of different shapes and sizes: spheres (diameters: $70 \mathrm{~mm}$ [five pieces], $40 \mathrm{~mm}$ [six pieces] and $5 \mathrm{~mm}$ [six pieces]); disks (20 $\mathrm{mm}$ in diameter and 10 $\mathrm{mm}$ high [six pieces] and $20 \mathrm{~mm}$ in diameter and $2 \mathrm{~mm}$ high [six pieces]); boxes $(100 \times 100 \times 47 \mathrm{~mm}$ [five pieces], $35 \times 35 \times 35 \mathrm{~mm}$ [six pieces] and $14 \times 14 \times 14 \mathrm{~mm}$ [six pieces]); thin pieces of cloth $(90 \times 80 \mathrm{~mm}$ [six pieces]); and pins ( $3 \mathrm{~mm}$ in diameter and $42 \mathrm{~mm}$ in length [six pieces]). Zero to 10 points is added according to the time taken to finish the task. We classified the items into three categories by size: large-large-sized ball, middle-sized ball and large box; middle-middle-sized and small boxes, wooden disc and small cloths; and small—small metal disc, small ball and pins.

We examined the relationship between Nalebuff's three clinical stages and dysfunction of the hand. Statistical analysis was performed by Mann-Whitney's $\mathrm{U}$ test and the $p$ value $<0.05$ was used to indicate significant difference.

This study was approved by the hospital ethics committee, and informed consent was obtained from all subjects according to the Helsinki Declaration.

\section{Results}

Thirty-two RA patients (27 women and 5 men, 61 hands) were evaluated. Their mean age was $61.1 \pm 8.8$ years (range, 39 - 82 years), and mean disease duration was $15.3 \pm 8.8$ years (range, 3 - 28 years). We excluded 2 hands because the thumbs had greater involvement at the IP joint than the MP joint. As a result, the clinical staging for thumb type I deformity was: early, 45 hands; moderate, 10 hands; and severe, 4 hands (Table 1).

The mean MKI scores were 8.9, 7.5 and 4.75 in the early, moderate and advanced stage groups, respectively. There were statistically significant differences in mean MKI scores between the early and moderate stage groups, and the moderate and advanced stage groups (Figure 1). 
The STEF results for the large objects category showed there was a tendency for the early stage group to have higher scores than the moderate stage group and the moderate stage group to have higher scores than the advanced stage group (early vs. moderate: $p=0.070$, moderate vs. advanced: $p=0.075$ ). For the middle-sized objects, the STEF scores of the early stage group were significantly higher than those of the moderate stage group, and the points of the moderate stage group were significantly higher than those of the advanced stage group. For the small-sized objects, there was tendency for the early stage group to score higher than the moderate stage group ( $p=0.55$ ); furthermore, the moderate stage group had significantly higher STEF scores than the advanced stage group. The mean total STEF scores were 92.9, 85.7 and 61.3 in the early, moderate and advanced stage groups, respectively. There were significant differences in total STEF scores between the early and moderate stage groups, and between the moderate and advanced stage groups (Figure 2).

\section{Discussion}

The most frequent rheumatoid thumb deformity is the type I (boutonniere) deformity [4] [5] [12]. It is initiated by proliferative MP joint synovitis bulging dorsally. The synovitis results in attenuation of the extensor pollicis brevis tendon insertion, the capsule and collateral ligaments, and stretching of the extensor hood with bony ero-

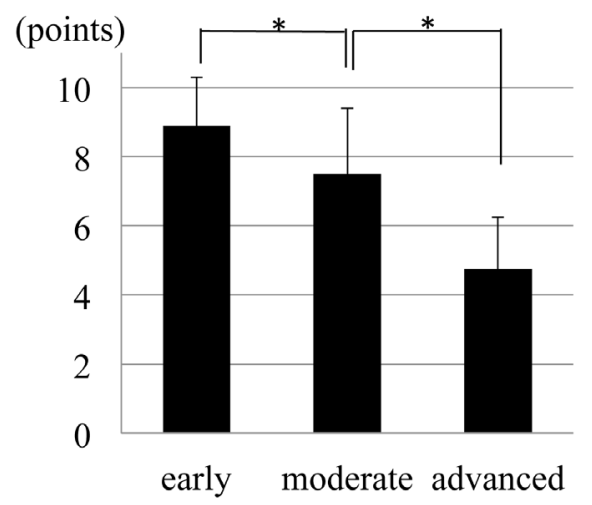

Figure 1. Modified Kapandji Index (MKI) score by clinical stage. Early: early stage group; moderate: moderate stage group; advanced: advanced stage group. The data are mean \pm $\mathrm{SD}$ (error bars). ${ }^{*} p<0.05$.

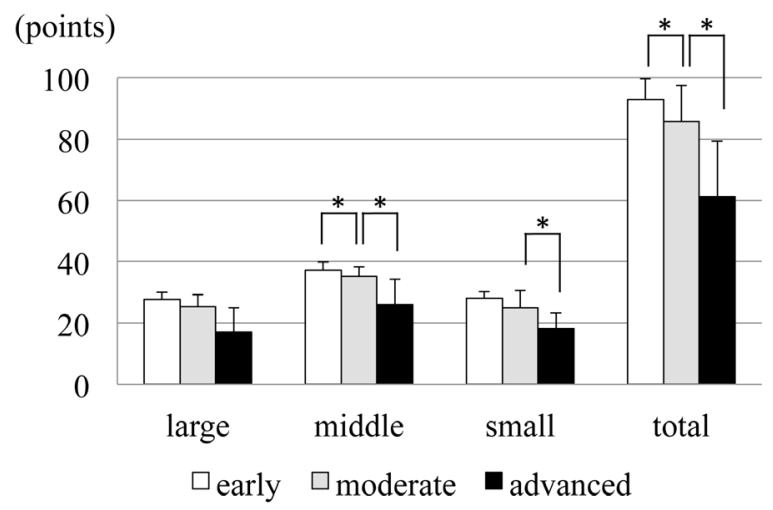

Figure 2. Simple Test for Evaluating Hand Function (STEF) scores for different sized objects by clinical stage. Early: early stage group; moderate: moderate stage group; advanced: advanced stage group; large: ability to grasp and carry largesized objects; middle: ability to pinch and carry middle-sized objects; small: ability to pinch and carry small-sized objects; total: total score for STEF. The data are mean \pm SD (error bars). ${ }^{*} p<0.05$. 
Table 1. Demographic characteristics of patients.

\begin{tabular}{|c|c|c|c|c|c|c|c|}
\hline \multirow{2}{*}{ Patient } & \multicolumn{2}{|c|}{ Sex $(\%)$} & \multirow{2}{*}{$\begin{array}{l}\text { Age } \\
\text { (Years) }\end{array}$} & \multirow{2}{*}{$\begin{array}{l}\text { Disease Duration } \\
\text { (Years) }\end{array}$} & \multicolumn{3}{|c|}{ Staging for Type I Deformity (\%) } \\
\hline & Female & Male & & & Early & Moderate & Severe \\
\hline & 16 & 84 & $61.1 \pm 8.8$ & $15.3 \pm 8.8$ & 76 & 17 & 7 \\
\hline
\end{tabular}

sion. The extensor pollicis longus (EPL) is displaced ulnar-wards and palmar-wards. These losses of dorsal support result in subluxation of the proximal phalanx on the metacarpal and concomitant hyperextension of the IP joint from the altered pull of both intrinsic muscles and the EPL. The first metacarpal becomes radially abducted to compensate for the MP flexion. Each pinch action then sets up a vicious cycle of MP joint flexion and IP joint hyperextension. This results in subluxation and eventual dislocation of the IP joint, resulting in the advanced type deformity [4] [5].

The scores for both MKI and STEF were reduced in parallel with the advancing stages of thumb deformity; that is, thumb function was reduced in line with progression of the deformity. The function of the carpometacarpal joint is important for grasping large objects. Reflecting this, there was no statistically significant difference in the STEF scores among the three clinical stages for the large objects group. Both IP and MP joints are more important for pinching ability. There were significant differences in STEF score between the moderate and advanced stage groups for pinching both middle and small-sized objects, while the difference between the early and moderate stage group was only significant for pinching middle-sized objects. To pinch middle-sized objects, there must be some distance between the thumb pulp and long finger pulp, which requires preservation of the function of the MP joint. To pinch small-sized objects, the function of the IP joint may be more important than that of the MP joint, judging from the STEF results with the small objects category. In type I thumb deformity, the MP joint was fixed in the flexion and adduction position, so pinching function for small-sized objects may be preserved, even if the MP joint was fixed.

It has been reported that the use of a thumb orthosis was effective in relieving pain in type I deformity and did not negatively affect hand function [13]. Also, the usefulness of surgical treatment according to the stage of deformity has been reported, but the findings were based on the recurrence rate of the deformity and patient satisfaction [5]. We measured hand function in type I thumb deformity of RA using both MKI and STEF, and showed that hand function is reduced with advancing clinical stage; in other words, the traditional Nalebuff's staging system is also useful for reflecting the level of thumb function. Like pain and satisfaction, hand function is important to the patient. By adding assessment of hand function, a more detailed workup for treatment for rheumatoid thumb deformity will be possible, which may ultimately help advance treatment of this condition.

\section{Conclusion}

Hand function was reduced in parallel with the advancing stages of type I deformity of the rheumatoid thumb. Therefore, the traditional Nalebuff's staging system is also useful for reflecting the level of thumb function.

\section{Disclosures}

All authors declare no conflicts of interest.

\section{References}

[1] King, J.A. and Tomaino, M.M. (2001) Surgical Treatment of the Rheumatoid Thumb. Hand Clinics, 17, 275-289.

[2] Nalebuff, E.A. (1968) Diagnosis, Classification and Management of Rheumatoid Thumb Deformities. Bulletin of the Hospital for Joint Diseases, 29, 119-137.

[3] Clayton, M.L. (1962) Surgery of the Thumb in Rheumatoid Arthritis. Journal of Bone and Joint Surgery, 44, 13761386.

[4] Feldon, P., Terrono, A.L., Nalebuff, E.A. and Millender, L.H. (2011) Rheumatoid Arthritis and Other Connective Tissue Diseases. 6 Edition, In: Wolfe, S.W., Hotchkiss, R.N., Pederson, W.C. and Kozin, S.H., Eds., Green's Operative Hand Surgery, Elsevier, Philadelphia, 1993-2066. http://dx.doi.org/10.1016/b978-1-4160-5279-1.00061-7

[5] Terrono, A., Millender, L. and Nalebuff, E. (1990) Boutonniere Rheumatoid Thumb Deformity. Journal of Bone and Joint Surgery, 15, 999-1003. http://dx.doi.org/10.1016/0363-5023(90)90032-M 
[6] Ratliff, A.H. and Davies, R.A. (1971) An Extension to an Operating Table for Hand Surgery. Hand, 3, 112-113. http://dx.doi.org/10.1016/0072-968X(71)90022-2

[7] Arnett, F.C., Edworthy, S.M., Bloch, D.A., Mcshane, D.J., Fries, J.F., et al. (1988) The American Rheumatism Association 1987 Revised Criteria for the Classification of Rheumatoid Arthritis. Arthritis \& Rheumatism, 31, 315-324. http://dx.doi.org/10.1002/art.1780310302

[8] Kapandji, A.I. (2003) The Clinical Evaluation of the Upper Limb Joints' Function: Back to Hippocrates. Hand Clinics, 19, 379-386. http://dx.doi.org/10.1016/S0749-0712(03)00029-5

[9] Lefevre-Colau, M.M., Poiraudeau, S., Oberlin, C., Demaille, S., Fermanian, J., et al. (2003) Reliability, Validity, and Responsiveness of the Modified Kapandji Index for Assessment of Functional Mobility of the Rheumatoid Hand. Archives of Physical Medicine and Rehabilitation, 84, 1032-1038. http://dx.doi.org/10.1016/S0003-9993(03)00128-X

[10] Kaneko, T., Hirano, K., Muraki, T. and Kuriyama, Y. (1986) Development and Standardization of the Hand Function Test. Kobe University, Kobe, 37-42.

[11] Yamanaka, H., Kawahira, K., Arima, M., Megumi, S., Seiji, E., et al. (2005) Evaluation of Skilled Arm Movements in Patients with Stroke Using a Computerized Motor-Skill Analyser for the Arm. International Journal of Rehabilitation Research, 28, 277-283. http://dx.doi.org/10.1097/00004356-200509000-00013

[12] Toyama, S., Tokunaga, D., Fujiwara, H., Oda, R., Kobashi, H., et al. (2014) Rheumatoid Arthritis of the Hand: A FiveYear Longitudinal Analysis of Clinical and Radiographic Findings. Modern Rheumatology, 24, 69-77. http://dx.doi.org/10.3109/14397595.2013.854054

[13] Silva, P.G., Lombardi Jr., I., Breitschwerdt, C., Poli Araujo, P.M. and Natour, J. (2008) Functional Thumb Orthosis for Type I and II Boutonniere Deformity on the Dominant Hand in Patients with Rheumatoid Arthritis: A Randomized Controlled Study. Clinical Rehabilitation, 22, 684-689. http://dx.doi.org/10.1177/0269215508088989 